\title{
Webquest "A cana de açúcar e o meio ambiente"
}

Webquest "Sugarcane and the environment"

\section{Oribes Pancracio de Souza ${ }^{1}$, Maria Celina Piazza Recena ${ }^{2}$}

${ }^{1}$ Secretaria de Educação do Estado do Mato Grosso do Sul (SED/MS).

${ }^{2}$ Universidade Federal de Mato Grosso do Sul, Centro de Ciências Exatas e Tecnologia, Departamento de Química. Cidade Universitária s/n - Campus de Campo Grande Universitário 79070-900 - Campo Grande, MS - Brasil - Caixa-postal: 549

\begin{abstract}
His article makes use of a public Webquest in the discipline of chemistry in the second year of high school in the project "CONNECT SCHOOL". Chemistry professor created a Webquest that their task was drafted in an essay about the deployment of ethanol plants in the Pantanal region. Issue addressed in the legislative assembly in the state with approval only at the second attempt in which they presented such a project. The Webquest was made available to students within a "Wikispaces" which were posted on the activities developed throughout the project.
\end{abstract}

Resumo. Esse artigo torna público o uso de uma Webquest na disciplina de química no segundo ano do ensino médio no projeto "CONECTA ESCOLA". O professor de química criou uma Webquest para que em sua tarefa fosse elaborada uma redação a respeito da implantação de usinas de álcool na região pantaneira. Assunto abordado na assembleia legislativa no estado com aprovação somente na segunda tentativa em que se apresentou tal projeto. A Webquest foi disponibilizada aos alunos dentro de uma "Wikispaces" na qual foram postadas as atividades elaboradas ao longo do projeto.

\section{Introdução}

A proposta de exploração da sala de tecnologia como um recurso didático na tentativa de promover um aprendizado significativo nas escolas da rede estadual de ensino é uma iniciativa da secretária de educação do estado prevista na reorganização do plano estratégico das salas de tecnologias das escolas estaduais no projeto "CONECTA ESCOLA". Busca-se definir e programar ações com intenção de melhorar o uso das salas de tecnologias educacionais (STE) e garantir um ensino de qualidade para os alunos.

Nessa proposta a importância dada as questões relacionadas ao meio ambiente e a conscientização ambiental reflete a preocupação atual com as questões ambientais Nobre et al 
(2011).

A turma escolhida apresenta os seguintes problemas de aprendizagem: dificuldades em interpretar o enunciado de problemas de química e física, dificuldades em analisar gráficos e tabelas comuns na geografia e problemas de articulação de suas ideias ao desenvolver atividades em que seja necessária a produção de texto, seja qual for seu gênero.

Essas dificuldades apresentadas segundo Caldas (2006) já foram identificadas em pesquisas feitas a partir de avaliações como do Sistema Nacional de Avaliação da Educação Básica (SAEB) e do Exame Nacional do Ensino Médio (ENEM) em outros alunos do ensino médio.

A partir dessas dificuldades identificadas neste turno, foi elaborado um material didático que possa melhorar estes aspectos da aprendizagem. Existem vários recursos que poderiam ser empregados para essa finalidade, porém, no presente trabalho a Webquest foi escolhida para inserção do conteúdo de química de forma contextualizada ao se tratar de um tema relacionado à necessidade de conservação e preservação do meio ambiente, explorando os recursos da internet e suas fontes de informação.

Contextualizada não só com a finalidade de preparar o aluno para o exercício da cidadania como afirmam Santos e Schnetzler (1997), mas igualmente para o exercício consciente, ativo e interativo da cidadania. Ativo no sentido de participar e assumir as responsabilidades sociais que são impostas a partir do momento que está consciente do que significa para o meio ambiente a decisão do uso de uma determinada tecnologia. Nesse caso trata-se da possibilidade de implantação de usinas de álcool no Pantanal.

Para as aulas de química na sala de tecnologia foi criada uma Webquest do tipo julgamento e avaliação, segundo a taxonomia de Bloom (1972), questionando a possibilidade de instalação de usinas de álcool na região pantaneira. Considerando os aspectos ambientais, sociais e econômicos desta iniciativa na tarefa proposta os alunos elaboraram uma redação em que deveria expor sua opinião sobre este tema, fundamentando seus pontos de vista sobre o assunto a ser discutido.

Para Lima et al (2009) o Brasil tem grande potencial produtor de álcool combustível para atender ao demanda do mercado interno e externo, mas o plantio de cana-de-açúcar no planície pantaneira se constitui um sério risco ambiental. Pois é um ambiente que não possui aptidão para uso agrícola e sua preservação depende do uso e cobertura da terra em sua bacia hidrográfica.

Quando se desenvolveu o conteúdo relacionado à termoquímica e as diferentes fontes de energia, dentre elas o álcool combustível, foi elaborada uma Webquest a respeito da 
possibilidade de produção de álcool na região chamada de Pantaneira. O material didático foi aplicado em uma turma do segundo ano do ensino médio no turno noturno.

A principal característica de uma Webquest, esta em orientar os alunos em um processo investigativo e seleção de conteúdo a partir da cooperação entre os alunos. Nela se cria um ambiente orientado, onde seu objetivo é evitar que o aluno se perca na infinidade da internet e consiga desenvolver suas atividades com êxito (DODGE 1995).

Esse material didático explora a interações entre aluno e professor, aluno e o conhecimento e a interação entre os alunos, fazendo com que ocorra a construção do conhecimento em uma perspectiva interacionista. Segundo Vygotsky (2010) o papel da interação social contribui de forma efetiva para um melhor processo de aprendizagem nos indivíduos a partir da interação entre si e com o objeto de ensino.

Considerando a interação social e o trabalho cooperativo que se espera ocorra em uma ferramenta pedagógica como a Webquest, o processo de ensino se dá segundo afirma Vygotsky (2010) com uma aprendizagem a partir das relações sociais, por meio do convívio com outras pessoas.

Segundo Dodge (2002) consideram-se dois tipos de Webquest, a saber:

- De curta duração: necessita-se de uma a três aulas para sua resolução, seus objetivos estão concentrados em proporcionar aos alunos contato com o novo conhecimento, aquisição e integração deste novo conhecimento apresentado.

- De longa duração: ocorre entre uma semana até mesmo meses de trabalho, seus objetivos são aprofundar e promover a integração de um número maior de informações e conceitos.

Ainda para Dodge (1995) uma Webquest precisa ser composta de:

1. Uma introdução: fornece as informações necessárias e prepara o cenário, são as informações iniciais, deve ser um texto que provoque o aluno e estimule-o

2. Uma tarefa: deve ser viável, ou seja, algo que o aluno perceba que pode realizar seja interessante e relevante para o mesmo.

3. Uma descrição do processo: são orientações que o aluno deve seguir para completar a tarefa. É uma descrição clara das etapas que o aluno segue.

4. Um conjunto de recursos: o professor seleciona as informações que considera relevante, obtidas de fonte confiável, necessárias para que o aluno possa completar a tarefa. É um conjunto de informações geralmente em forma de links disponíveis na internet. 
5. Um método de avaliação: esclarecer qual a maneira que o trabalho do aluno será avaliado. Não deixar qualquer dúvida quanto a este aspecto. O ideal é uma forma de avaliação que valorize os aspectos quantitativos e qualitativos da tarefa.

6. Uma conclusão: resumo das atividades propostas, o propósito da atividade, demonstrar o que aprenderam e motivá-los a continuar suas investigações e pesquisas.

7. Os créditos: indica quais fontes foram utilizadas, nomes dos autores e se for o caso, nome, endereço e e-mail da escola.

Com relação à natureza da tarefa de uma Webquest, ela pode ser classificada por Dodge (2002) a partir da "Taxonomia de Bloom" da seguinte maneira:

1. Redigir o que se leu (contar). Exige-se nesse caso a transmissão do que se aprendeu, é uma tarefa mais simples, o trabalho final deve ser diferente da informação inicial.

2. Compilação de dados. Exige-se que os alunos desenvolvam e articulem seus critérios para seleção dos itens agregados durante o processo de resolução da tarefa.

3. Mistério (papel de detetive). Exige-se assimilação de informação de diferentes fontes eliminando-se as pistas falsas que poderão inicialmente parecer respostas, mas após a sua análise acabaram sendo desconsideradas.

4. Jornalismo (papel de repórter). Exige-se que a partir da incorporação de opiniões divergentes os alunos enriqueçam seus conhecimentos.

5. Criar um produto ou planejar uma ação. Exige-se a descrição de um produto considerado necessário para alguém em algum lugar. Deve ser limitado, por exemplo, de forma orçamentária ou legal.

6. Produtos criativos (criar um poema, canção, uma pintura). Exige-se a produção de algo em um determinado formato: uma música, uma peça de teatro, um quadro, algo que valorize a criatividade e a forma de expressão dos alunos.

7. Criar Consenso. Baseia-se em opiniões reais e atuais. Exige-se nesse tipo de tarefa os alunos deverão articular e acomodar em seu trabalho diferentes pontos de vistas.

8. Persuasão. Exige-se o desenvolvimento e a apresentação de um caso convincente que pode assumir várias formas. Pode por exemplo ser um comunicado para imprensa, uma carta aos vereadores da cidade, um pôster, um vídeo.

9. Autoconhecimento (reflexão sobre quem é; questões éticas e morais; como melhorar determinadas facetas, etc.). É uma forma de motivar à reflexão sobre quem são procurando e definindo objetivos em longo prazo. 
10. Tarefas analíticas (identificar semelhanças e diferenças). Exige-se que os alunos concentrem sua atenção em um ou vários aspectos, identifique semelhanças e diferenças, reflitam sobre as implicações dessas diferenças e semelhanças.

11. Julgar/avaliar. Exige-se a disposição de um conjunto de regras de condutas ou critérios para se formar a sua opinião. Espera-se que os alunos trabalhando em grupo, explorando-se as informações fornecidas possam elaborar os seus próprios critérios de avaliação e julgamento.

12. Tarefas científicas/método científico. Exige-se a produçãode um relatório científico, incluindo a definição de hipóteses fundamentadas na compreensão das informações obtidas.

Para Dodge (1995) em uma Webquest bem estruturada é possível que o aluno seja capaz de transformar um conjunto de informações em conhecimento. Sua utilização favorece a construção do conhecimento a partir das interações sociais entre os alunos, se constituindo desta forma uma atividade colaborativa de cunho sócio construtivista. As interações sociais são consideradas por Vygotsky (2010) importantes para a construção do conhecimento.

\section{Metodologia}

$\mathrm{O}$ aluno em um primeiro momento acessou a Wikispaces criada para desenvolver todas as atividades previstas no projeto "CONECTA ESCOLA". Na Wikispace da disciplina de química foi postado um link para a Webquest sobre o tema álcool no pantanal. O aluno então passou a seguir as orientações de como desenvolver sua tarefa. No segundo momento da atividade acessou os links disponíveis nos recursos da Webquest, em um terceiro momento iniciou a sua produção de texto.

Uma Wikispace pode ser um recurso interessante, pois é uma ferramenta do tipo web 2.0 na qual o aluno pode produzir e publicar o conhecimento adquirido. Para Alexander (2006, p.33) e Costa et al (2011) em uma Wikispace sua utilização ocorre de forma colaborativa e o conhecimento é construído e compartilhado coletivamente, tendo-se liberdade para utilizar, editar, reeditar. É um conceito conhecido como colaborative working. O texto elaborado foi postado na Wikispaces para ser analisado e o professor orientou o aluno a fazer as correções necessárias neste documento. Todas as disciplinas envolvidas no projeto CONECTA ESCOLA postaram suas atividades nessa Wikispace.

Posteriormente foi feito um debate em sala para a socialização das diferentes opiniões usando a técnica de grupos de oposição. Segundo Rosa (2010) com esta técnica que 
explora o espírito de competição dos alunos, é preciso uma dedicação maior no estudo do assunto a ser debatido em sala.

\section{O Material Didático: A Webquest}

Nessa proposta com a Webquest do tipo de julgamento e avaliação, “A CANA DE AÇUCAR E O MEIO AMBIENTE", a qual aluno pode acessar a qualquer momento, em sua introdução é feito um levantamento sobre os aspectos históricos relacionados a essa cultura no Brasil e no estado (figura 1).

Figura 1-Página com introdução sobre o tema de pesquisa



Fonte: Dados do autor

$\mathrm{Na}$ tarefa é feito a descrição das atividades que deveriam ser desenvolvidas e como deveriam utilizar as fontes de informações escolhidas para consulta na elaboração da tarefa proposta (figura 2).

Figura 2- Página com a descrição das tarefas a serem executadas na Webquest

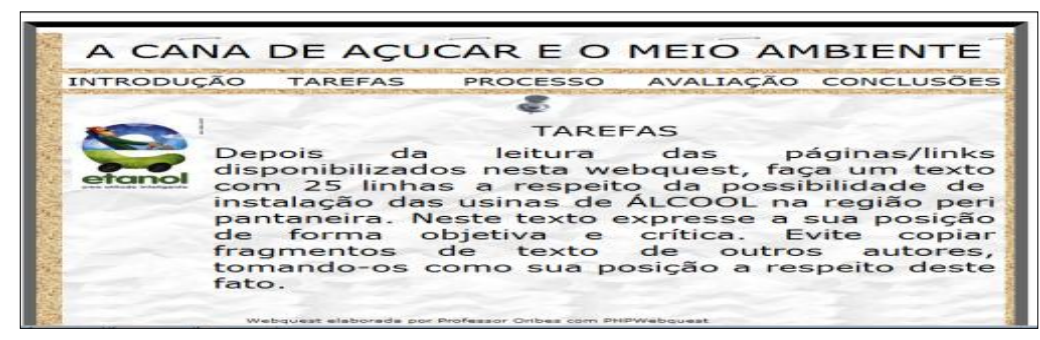

Fonte: Dados do autor

No Processo os alunos têm as orientações de como deveriam executar a tarefa proposta, tendo a sua disposição um conjunto de páginas (links) relacionado ao tema do trabalho (Figura 3).

Figura 3- Página com processo e os links disponíveis para consulta



Fonte: Dados do autor 
No item avaliação foi descrita como as atividades seriam avaliadas com a especificação dos principais itens a serem observados na tarefa proposta (figura 4).

Figura 4. - Página da forma de avaliação da tarefa

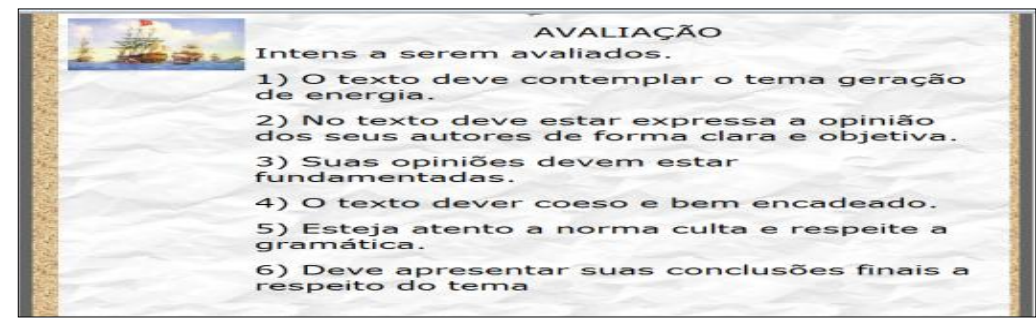

Fonte: Dados do autor

A conclusão esclarece as razões do trabalho, mostrando aos alunos o que foi possível aprender e qual deve ser sua postura diante de questões ambientais (Figura 5).

Figura 5- Página com a conclusão da Webquest Proposta

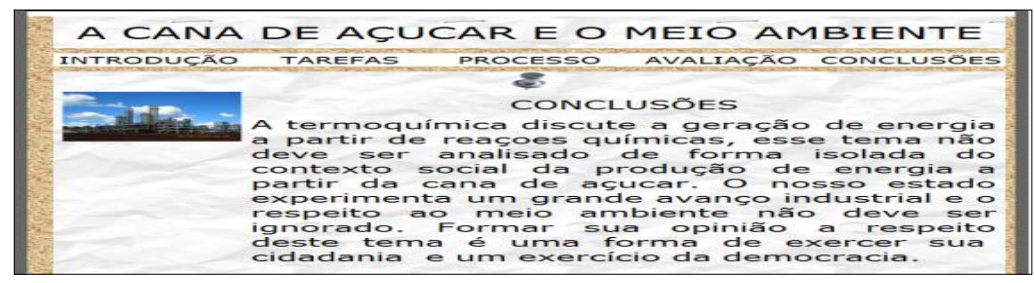

Fonte: Dados do autor

\section{Análise dos Resultados}

No trabalho os resultados foram obtidos considerando-se dois instrumentos de coleta de dados: 1) Produção de texto em dupla, a ser elaborado na forma de texto argumentativo a respeito do tema proposto, 2) Debate em sala sobre a produção de álcool combustível na região Peri Pantaneira, com o titulo: Álcool no Pantanal: o que você pensa?

Assim analisou-se o texto e os comentários dos alunos no debate, com a finalidade de identificar o caminho percorrido pelo estudante para a construção do conhecimento. Segundo Almeida e Silva (2007, p.157-175) estas formas de linguagens, podem demonstrar ou apontar para os pontos da proposta de intervenção que o aluno julga mais relevante e, portanto podem contribuir para a sua aprendizagem.

A produção de álcool em nossa região é uma importante atividade econômica geradora de emprego e faz parte do nosso cotidiano. Por envolver diversos aspectos do dia a 
dia dentre eles, econômico e ambiental ao elaborar este material didático procurou-se desenvolver de forma contextualizada e interdisciplinar. A produção de texto foi proposta em conjunto com a disciplina de português, que esclareceu e trabalhou com os alunos quais os aspectos que um texto dissertativo argumentativo deve ter.

Nesta Webquest sobre o álcool, em sua tarefa após a consulta e leitura dos textos escolhidos (recursos), solicitou-se aos alunos a produção de um texto do tipo dissertativo argumentativo (redação) sobre o tema: ALCOOL NO PANTANAL. Esses textos foram postados na Wikispaces e analisados em conjunto com a professora de português da escola. Utilizando-se uma forma de pesquisa qualitativa, a fim de se identificar quais argumentos fundamentaram as concepções formadas pelos alunos sobre o tema proposto. A análise e o tratamento dos dados seguiram os parâmetros da análise de conteúdo com categorias determinadas "a posteriori".

\section{Resultados e Discussão}

Os alunos não apresentaram dificuldades para trabalhar com a Webquest, conseguiram reconhecer e acessar todos os links disponibilizados no material didático proposto. Com isso foi possível à produção do texto solicitado na tarefa, organizando os alunos em duplas. Nessa turma foi produzido um total de nove textos, sendo que apenas um deles foi favorável à instalação de usinas no pantanal. O principal argumento é a geração de emprego, conforme o texto abaixo:

Somos favoráveis à implantação de usinas, pois isso pode gerar muitos empregos...

No referido texto é salientado a importância de se buscar novas formas de desenvolvimento, em que a tecnologia empregada atualmente pode evitar danos ambientais ao pantanal, concepções verificadas no texto a seguir:

...também o projeto pretende propor uma alternativa de desenvolvimento para os municípios da região do norte do estado. Sustenta também os riscos ambientais serão evitados pela tecnologia disponível e pelo controle sobre o manejo da cana e seus resíduos. Consequentemente com os cuidados previsto na lei e com a atual tecnologia empregada em usinas, a cana-de-açúcar é a melhor opção para uma região cujas principais atividades econômicas são a pecuária e a soja.

Os textos elaborados contrários a esta atividade, fundamentam-se nos mesmos argumentos, destacando os riscos que o vinhoto pode representar para o meio ambiente e os danos que uma monocultura pode causar: 
As usinas podem descarregar nos cursos das águas o vinhoto, um líquido tóxico e residual do processo de destilação do álcool da cana-de-açúcar.

As usinas também podem despejar no solo e nos rios outros poluentes, como a água cáustica utilizada na lavagem da cana e anticorrosivos e detergentes aplicados nos equipamentos das instalações. A plantação de cana não é bom para o meio ambiente, por que o cultivo de cana pode causar redução do biodiversidade da região do Pantanal.

A atividade provoca erosão e degradação do solo, acarreta na diminuição de microorganismos na terra, ainda mais quando a plantação é queimada antes da colheita, $e$ pode comprometer os recursos hídricos com o despejo de produtos químicos como pesticidas e de grandes quantidades de vinhoto.

Em um dos textos ainda persiste a ideia de que se pratica a queimada da cana para então ser feito o seu corte, como mostrado a seguir:

Na cana, o processo mais perverso é a queima da palha, causando o desmatamento. As queimadas liberam para a atmosfera partículas e gases prejudiciais não só ao homem como ao meio ambiente.

Os argumentos utilizados na produção dos textos correspondem aos mesmos dos recursos disponibilizados na Webquest e foram igualmente explorados durante o debate. Nessa ocasião em sala não ocorreu mudanças significativas na forma de argumentação dos alunos, sendo evidentes as mesmas preocupações com o meio ambiente e as consequências dessa atividade para o pantanal.

\section{Comentários finais}

O mérito da proposta foi promover a interação entre os alunos com a discussão de um tema com caráter sócio cientifico que pode influenciar o seu cotidiano. Conhecer e debater sobre o tema proposto possibilitou o desenvolvimento de uma atividade interdisciplinar contextualizada, sendo necessária a utilização dos conceitos relacionados à produção de texto característicos da disciplina de português, aplicação de conceitos relacionados à geografia, pois se fez necessário identificar as diferentes regiões do pantanal e conceitos de química referentes à termoquímica. Buscando despertar no aluno o senso crítico e a capacidade de análise e tomada de decisão para questões de caráter sócio cientificas que se apresentam em seu cotidiano. 


\section{Referência}

ALENXANDER, B. (2006). Web 2.0: A new wave of innovation for teaching and learning? Educause Review, 41(2), 32-44.

ALMEIDA, J. P.M., SILVA, C. S. (2007) Linguagens, Leituras e Ensino de Ciência. 1.ed. Campinas. Mercado de Letras.. p.157-175.

BLOOM, B. S. (1972) Taxonomia dos objetos educacionais. Porto Alegre: Editora Globo1972.

CALDAS, G. M. ( 2006) Escola e leitura crítica do mundo. Educação e Sociedade.Campinas. Vol. 27, no. 94. p. 117-130. Acesso em 21 junho de 2011, disponível em <http:www.cedes.unicamp.br> .

COSTA, R. G.; PASSERINO, L. M.; ARAÚJO, RESENDE T. M. (2011) Aprendizagem colaborativa baseada em wiki no estudo de conceitos da termodinâmica. In: Anais do XVII WIE-Workshop de Informática na Escola. Aracaju-SE, p. 1178-1187.

DODGE, B. (1995). Some Thoughts About WebQuests. [online]. [cited 14.11.2000]. Available from World Wide Web: http://edweb.sdsu.edu/courses/EDTEC596/About_WebQuests.html. acesso em 12/05/2011.

DODGE, B.(2002). Taskonomia: Uma Taxonomia de Tarefas. < http://webquest.sdu.edu/taskonomy.html> Acesso em 15 de junho de 2011.

LIMA, A.; AGUIAR, D. A.; RUDORFF, B. F. T.; SHIMABUKURO, Y. E.; ADAMI, M.(2009) Dinâmica espaço-temporal e caracterização ambiental do cultivo da cana-de-açúcar na Bacia Pantaneira. Geografia (Rio Claro), v. 34, n. 1, p. 193-202. Disponível em: <http://urlib.net/dpi.inpe.br/plutao@80/2009/07.13.14.23.38>. Acesso em: 01 nov. 2011.

NOBRE, I. A. M. ; ROSARIO, K. ; SIQUEIRA, A. ; NASCIMENTO, E. L.. CONSCIÊNCIA AMBIENTAL: OBJETO DE APRENDIZAGEM COMO APOIO AO ENSINO DE MEIO AMBIENTE. Em: $22^{\circ}$ Simpósio Brasileiro de Informática na Educação e $17^{\circ}$ Workshop de Informática na Escola, v. 1, p. 194-203, 2011.

ROCHA, L. R. (2007) A CONCEPÇÃO DE PESQUISA NO COTIDIANO ESCOLAR: POSSIBILIDADES DE UTILIZAÇÃO DA METODOLOGIA WEBQUEST NA EDUCAÇÃO PELA PESQUISA. Dissertação de mestrado-Universidade Federal do Paraná. Curitiba, Paraná.

ROSA, P. R. S. (2010). Instrumentação Para o Ensino de Ciências. Campo Grande: Editora UFMS.

SANTOS, W. L. P.; SCHNETZLER, R. P.(1997). Educação em Química, Compromisso com a Cidadania. 4ed. Editora Unijui, 169p.

VYGOTSKY, L.S.(2010) A Formação Social da Mente. 4.ed.São Paulo: Martins Fontes. 